\title{
ANALISIS EFISIENSI KETEL UAP PIPA AIR DENGAN KAPASITAS MAKSIMUM 10 TON PER JAM DENGAN BAHAN BAKU BATU BARA
}

\author{
Indriyani dan Ruslan Dalimunthe \\ Dosen Tetap pada Program Studi Teknik Mesin \\ Fakultas Teknik Universitas Sang Bumi Ruwa Jurai - Lampung (Indonesia)
}

\begin{abstract}
Abstrak
Pengendapan minyak atau pembentukan batu ketel akan dapat menimbulkan over heating (panas berlebih yang terjadi dalam pipa yang tersumbat oleh kotoran yang membatu menyebabkan pipa ai mudah pecah), konstuksinya lebih rumit, pemeliharaannya sulit dan membutuhkan biaya yang mahal, membutuhkan pemakaian pengatur otomatis pada beberapa alat operasional ketel, perlu berhati-hati betul menjaga tenangnya air dalam ketel, karena produksi uap sangat cepat. Metodologi penelitian yang dilakukan adalah dengan menggunakan ketel uap kapasitas 10 ton/jam, dengan data-data sebagai berikut: kapasitas 10,00 ton uap/jam, tekanan $25,00 \mathrm{~kg} / \mathrm{cm}^{2}$, temperatur uap keluar superheat $400,00{ }^{0} \mathrm{C}$, bahan bakar batubara, nilai pembakaran $5.300,00 \mathrm{kcal} / \mathrm{kg}$. Hasil penelitian sebagai berikut diantaranya: temperatur air pengisi masuk ekonomiser $80,00{ }^{\circ} \mathrm{C}$, temperature ruang bakar $1.420,00{ }^{0} \mathrm{C}$, pemakaian bahan bakar tiap jam $1.617,00 \mathrm{~kg} / \mathrm{jam}$, kalor yang diterima $6.938 .300,00 \mathrm{kcal} / \mathrm{k}$, temperature air keluar ekonomiser $170,00{ }^{0} \mathrm{C}$, luas panas ekonomiser $157,90 \mathrm{~m}^{2}$, tebal pipa ekonomiser 2,41 mm, jumlah pipa ekonomiser 84,00 buah, tebal pipa-pipa air $2,75 \mathrm{~mm}$, tebal pipa air pengumpul $5,88 \mathrm{~mm}$, luas panas pipa air $94,60 \mathrm{~m}^{2}$, jumlah pipa air 182,00 buah, tebal plat boiler drum 22,40 mm, tebal tutup boiler drum $26,50 \mathrm{~mm}$, tebal pipa superheat $2,260 \mathrm{~mm}$, jumlah pipa superheat $68,00 \mathrm{buah}$, luas panas superheat $84,20 \mathrm{~m}^{2}$, total luas panas boiler $336,70 \mathrm{~m}^{2}$, kebutuhan udara pembakaran setiap jam 9,6012 kg/bahan bakar, panas yang diserap oleh boiler $8.672 .875 \mathrm{kcal} / \mathrm{jam}$.
\end{abstract}

Kata kunci: efisiensi, ketel uap pipa air, pipa ekonomiser, boiler, pipa superheater

\section{EFFICIENCY EFFICIENCY ANALYSIS OF WATER PIPE WITH MAXIMUM CAPACITY 10 TON PER HOURS WITH RAW MATERIAL RAW MATERIALS}

\author{
Indriyani and Ruslan Dalimunthe \\ Permanent Lecturers of Mechanical Engineering \\ Engineering Faculty of Sang Bumi Ruwa Jurai - Lampung (Indonesia)
}

\begin{abstract}
Precipitation of oil or the formation of a boiler can lead to overheating (overheating occurring in pipes clogged by petrified stools causing the pipes to break easily), the construction is more complicated, maintenance is difficult and costly, requiring automatic regulation of some devices operational kettle, need to be careful really keep the calm water in the kettle, because the production of steam very quickly. The methodology of this research is to use a 10 ton / hour capacity boiler, with the following data: capacity of 10.00 tons of steam / hour, pressure $25.00 \mathrm{~kg} / \mathrm{cm}^{2}$, superheat exit steam temperature 400.00 0C, fuel coal, burning value $5,300.00 \mathrm{kcal} / \mathrm{kg}$. The research results are as follows: water temperature charger enter economizer $80,00{ }^{\circ} \mathrm{C}$, temperature of combustion chamber 1,420,00 ${ }^{\circ} \mathrm{C}$, fuel consumption every hour 1,617,00 kg / hour, calorie received $6,938,300,00 \mathrm{kcal} / \mathrm{k}$, water temperature out ekonomiser $170,00{ }^{\circ} \mathrm{C}$, heat of economizer $157,90 \mathrm{~m}^{2}$, thickness of pipe economist 2,41 mm, number of economical pipe 84,00, thick of
\end{abstract}


water pipe $2,75 \mathrm{~mm}$, thick of collector pipe $5.88 \mathrm{~mm}, 94.60 \mathrm{~m}^{2}$ hot water pipe, 182.00 pounds of water pipe, $22.40 \mathrm{~mm}$ drum plate thickness, drum cover drum thickness 26.50 $\mathrm{mm}$, superheat pipe thickness 2,260 mm, superheat pipe number 68,00, wide area superheat heat $84,20 \mathrm{~m}^{2}$, total heat of boiler $336,70 \mathrm{~m} 2$, requirement of burning air every hour 9,6012 kg/material, heat absorbed by boiler 8,672,875 kcal / hour.

Keywords: efficiency, water pipe boiler, economizer pipe, boiler, superheater pipes

\section{Pendahuluan}

\subsection{Latar Belakang Masalah}

Salah satu kelompok energi yaitu ketel uap yang dipergunakan untuk mengubah air menjadi uap, dimana uap ini berfungsi sebagai zat pemindah tenaga kalor, tenaga kalor yang dikandung di dalam uap ini dinyatakan dengan entalphi yang diperoleh uap dari proses pembakaran bahan bakar, yang mana kalor dipindahkan dari bahan bakar ke air dan uap melalui api dan gas menembus dinding-dinding pipa bidang pemanas (Setyardjo Djoko, 2013).

Ketel uap pipa-pipa air mempunyai keuntungan-keuntungan sebagai berikut: volume air relatif lebih kecil sehingga pemanasan awal lebih cepat, dalam waktu yang singkat telah dapat memproduksi uap, sanggup bekerja pada tekanan tinggi, mempunyai kapasitas total uap yang besar dan berat ketel yang relative ringan dibandingkan kapasitas ketel. Beberapa kelemahan pada ketel uap pipa-pipa air: air isian harus selalu bersih, lebih-lebih bila bekerja pada tekanan tinggi karena sedikit saja terjadi pengendapan minyak atau pembentukan batu ketel akan dapat menimbulkan over heating (panas berlebih yang terjadi dalam pipa yang tersumbat oleh kotoran yang membatu menyebabkan pipa ai mudah pecah), konstuksinya lebih rumit, pemeliharaannya sulit dan membutuhkan biaya yang mahal, membutuhkan pemakaian pengatur otomatis pada beberapa alat operasional ketel, perlu berhati-hati betul menjaga tenangnya air dalam ketel, karena produksi uap sangat cepat.

\section{Landasan Teori}

\section{Ketel Uap Pipa Air}

Ketel uap jenis ini mengalirkan uap di dalam pipa-pipa, sedangkan pemanasan air dilakukan gas-gas uap yang beredar disekitar pipa-pipa tersebut. Luas pemanas air ketel ini dibentuk oleh pipapipa yang berdinding tipis dengan garis tengah yang kecil. Oleh karena itu pada ketel pipa air terjadi transfer panas yang cepat pula. Ketel uap pipa-pipa air biasanya mempunyai tabung separator 
pada drum uap atas yang berfungsi untuk memisahkan antara uap dan air (Setyardjo Djoko, 2013).

\section{Sirkulasi Air Masuk Ketel}

Bagian bawah yang paling ujung pipa dihubungkan dengan pipa pengumpul (collector pipe), sedangkan pipa bagian atas menyambung dengan drum ketel uap. Pada bagian belakang pipa konveksi susunan pipa antara drum atas dengan dum bawah tersusun beberapa pipa seperti sebuah sisir yang tersusun rapi. Dengan bentuk dan konstruksi pipa tersebut boiler ini termasuk bersirkulasi alam. Terjadinya pemanasan di dalam ruang dapur tadi membuat penguapan di dalam pipa-pipa yang tersusun di dalam dapur menjadi gelembung-gelembung uap naik keatas menuju boiler drum. Oleh karena itu pada pipa ketel pipa air terjadi transfer panas yang cepat pula. Ketel uap pipa-pipa air yang biasanya mempunyai tabung separator pada drum uap atas yang berfungsi untuk memisahkan antara uap dan air (Setyardjo Djoko, 2013).

Pada ketel uap tekanan tinggi yang modern dan berkapasitas besar ada pemisahan mekanik (mechanical separation) yang membantu atau melengkapi pemisahan gravitasi dan berlangsung dalam dua langkah, yaitu langkah pemisahan primer dan sekunder
(A.T. Brown and S.M. Marco Mc Graw, 2012).

Disaat tekanan tinggi, dimana perbedaan antara densitas air dan uap kecil, digunakan gaya sentrifugal, yang lebih besar dari gaya gravitasi. Peralatan pemisah sentrifugal juga disebut pemisah stklon (cyclone separator) atau pemisah turbo (turbo separator). Alat ini melakukan pemisahan pada tekanan mendekati tekanan kritis. Pada separator sentrifugal, biasanya campuran yang datang dari pipa penaik dibelokkan secara tangensial ke bawah badan utama air.

\section{METODOLOGI PENELITIAN}

\subsection{Data-Data Ketel Uap}

Data-data diambil dari survei lapangan:

Kapasitas Terpasang $=$ 10,00 ton uap/jam

Tekanan Uap $=25,00 \mathrm{~kg} / \mathrm{cm}^{2}$

Temperatur Uap Keluar Superheat = $400,00{ }^{0} \mathrm{C}$

Bahan Bakar = Batubara

Nila Pembakaran $=5.300,00 \mathrm{kcal} / \mathrm{kg}$

\subsubsection{Temperatur Ruang Pembakaran}

Suhu udara masuk pembakaran $=30,00$ ${ }^{0} \mathrm{C}$

Panas jenis udara $=0,24 \mathrm{kcal} / \mathrm{kg}{ }^{0} \mathrm{C}$

\subsubsection{Luas Panas Ekonomiser}

Ekonomiser adalah suatu alat penukar panas yang digunakan sebelumair masuk 
ke dalam drum ketel yang berfungsi menaikan temperatur air, sebagai berikut: Temperatur gas asap masuk ekonomiser $\left(\operatorname{tg}_{1}\right)=320,00{ }^{0} \mathrm{C}$

Temperatur gas asap keluar ekonomiser $\left(\operatorname{tg}_{2}\right)=180,00{ }^{0} \mathrm{C}$

Temperatur air masuk ekonomiser $\left(\mathrm{tw}_{1}\right)=$ $60,00{ }^{0} \mathrm{C}$

Temperatur air keluar ekonomiser $\left(\mathrm{tw}_{2}\right)=$ $170,00{ }^{0} \mathrm{C}$

Kapasitas air mengalir tiap jam $\left(\mathrm{m}_{\mathrm{ek}}\right)=$ $10.000,00 \mathrm{~kg} / \mathrm{jam}$

$\mathrm{Cp}$ air $=1,00 \mathrm{kcal} / \mathrm{kg}{ }^{0} \mathrm{C}$

\section{Hasil Penelitian Dan Pembahasan}

\subsection{Hasil Penelitian}

\subsubsection{Perhitungan Ekonomisioner}

Menghitung kalor yang diterima air pengisi pada ekonomisioner kita menggunakan rumus:

$$
\mathrm{q}_{\mathrm{eko}} \quad=\mathrm{G} \cdot \mathrm{Cp} \cdot \Delta \mathrm{t} \mathrm{kcal} / \mathrm{jam}
$$

Dimana:

$$
\mathrm{q}_{\mathrm{eko}}=\text { Kalor yang diterima }
$$

oleh pengisi air

$\mathrm{G}=$ Massa air yang lewat ekonomisioner

$\mathrm{Cp} \quad=$ Panas jenis air $=1,00$ $\mathrm{kcal} / \mathrm{kg}{ }^{0} \mathrm{C}$

$\Delta \mathrm{t}=$ Selisih air masuk dan keluar ekonomisioner adalah $90,00{ }^{0} \mathrm{C}$ Maka:

$$
\begin{aligned}
\mathrm{q}_{\mathrm{eko}} & =\mathrm{G} \cdot \mathrm{Cp} \cdot \Delta \mathrm{t} \mathrm{kcal} / \mathrm{jam} \\
& =10 \cdot 000,00 \times 1,00 \times 90,00
\end{aligned}
$$

$$
=90.000,00 \mathrm{kcal} / \mathrm{jam}
$$

Dengan adanya sistem pemanas tersebut kita dapat menghemat pemakaian batubara sebanyak: 90.000,00 / 5.300,00 $=169,80 \mathrm{kcal} / \mathrm{jam}$.

\subsubsection{Perhitungan Boiler Drum}

Data-data boiler drum adalah sebagai berikut:

$$
\text { Tekanan boiler drum = }
$$

$25,00 \mathrm{~kg} / \mathrm{cm}^{2}$

Temperatur uap =

$229,00{ }^{0} \mathrm{C}$

Material boiler drum = $15,00 \mathrm{mo} 3$

Diameter luar boiler drum = $101,20 \mathrm{~cm}$

\subsubsection{Perhitungan Superheater}

\section{A. Superheat IA}

Dengan demikian tebal pipa dapat kita hitung dengan rumus:

$$
d t=\frac{p \cdot d o}{2 S+0,8 p}+C
$$

Dimana:

Semua ketentuan rumus sama dengan rumus mencari tebal pipa ekonomiser, dimana untuk temperature pipa 229,00 ${ }^{0} \mathrm{C}, \mathrm{S}$ adalah $15.000,00 \mathrm{lb} / \mathrm{in}^{2}=1054,50$ $\mathrm{kg} / \mathrm{cm}^{2}$.

Maka:

$$
d t \quad=\frac{p \cdot d o}{2 S+0,8 p}+C
$$




$$
\begin{gathered}
d t= \\
\frac{25 \times 5,7}{2 \times 1054,5+0,8 \times 41,36}+0,165 \\
=0,061+0,0165 \\
=0,226 \mathrm{~cm}
\end{gathered}
$$

Tebal pipa superheat sesuai perhitungan $=2,26 \mathrm{~mm}$.

Menurut normalisasi kita pakai pipa dengan

$$
\begin{aligned}
& \Phi \mathrm{do}=31,80 \mathrm{~mm} \\
& \Phi \mathrm{di}=26,91 \mathrm{~mm}
\end{aligned}
$$

\section{B. Colector Superheat IA}

Dengan demikian tebal pipa dapat kita hitung dengan rumus:

$$
\begin{aligned}
d t & =\frac{p \cdot d o}{2 S+0,8 p}+C \\
& =\frac{25 x 5,7}{2 x 1054,5+0,8} \\
0,165 & \\
& =0,061+0,0165 \\
& =0,568 \mathrm{~cm}
\end{aligned}
$$$$
=\frac{25 x 5,7}{2 x 1054,5+0,8 \times 25}+
$$

Tebal pipa colector sesuai perhitungan $=5,68 \mathrm{~mm}$.

Menurut normalisasi kita pakai pipa dengan

$$
\begin{aligned}
\Phi \text { do } & =20,90 \mathrm{~cm} \quad=31,80 \mathrm{~mm} \\
\Phi \mathrm{di} & =193,67 \mathrm{~mm}
\end{aligned}
$$

\section{Superheater IB}

Menurut normalisasi kita pakai pipa dengan:

$$
\begin{aligned}
& \Phi \mathrm{do}=38,00 \mathrm{~mm} \\
& \Phi \mathrm{di}=31,00 \mathrm{~mm}
\end{aligned}
$$

\section{Colector Superheat IB}

Menurut normalisasi kita pakai pipa dengan:

$$
\begin{aligned}
& \Phi \mathrm{do}=38,00 \mathrm{~mm} \\
& \Phi \mathrm{di}=31,00 \mathrm{~mm}
\end{aligned}
$$

\section{E. Superheater II}

Dimana ketentuan lain sama seperti superheater IB, untuk temperature uap pada superheat II, $400^{\circ} \mathrm{C}$, menurut table P5. $S=14.000,00 \mathrm{lb} / \mathrm{in}^{2}=984,20$ $\mathrm{Kg} / \mathrm{cm}^{2}$.

Maka:

$$
\begin{aligned}
& d t \quad=\frac{p \cdot d o}{2 S+0,8 p}+C \\
& =\frac{25 \times 3,18}{2 \times 984,2+0,8 \times 25}+0,165 \\
& =0,061+0,0165 \\
& =0,23 \mathrm{~cm}
\end{aligned}
$$

Tebal pipa superheat II menurut hasil perhitungan $=23,00 \mathrm{~mm}$

Menurut normalisasi kita pakai pipa dengan:

$$
\begin{aligned}
\Phi \mathrm{do} & =38,00 \mathrm{~mm} \\
\Phi \mathrm{di} & =31,00 \mathrm{~mm}
\end{aligned}
$$

\section{F. Colector Superheat II}

Mengitung tebal pipa collector superheater $\mathrm{n}$ dengan ketentuan lain sama seperti superheater IB, diman untuk temperature uap $400,00{ }^{\circ} \mathrm{C}$, menurut table P5. $\mathrm{S}=14.000,00 \mathrm{lb} / \mathrm{in}^{2}=984,20 \mathrm{~kg} / \mathrm{cm}^{2}$. Maka: 


$$
\begin{aligned}
d t \quad & =\frac{p \cdot d o}{2 S+0,8 p}+C \\
& =\frac{25 x 5,7}{2 x 984,2+0,8 \times 25}+
\end{aligned}
$$$$
0,165
$$

$$
\begin{aligned}
& =0,061+0,0165 \\
& =0,568 \mathrm{~cm}
\end{aligned}
$$

Tebal pipa colector sesuai perhitungan $=5,68 \mathrm{~mm}$.

Ukuran pipa collector berdasarkan normalisasi:

$$
\begin{aligned}
\Phi \text { do } & =22,70 \mathrm{~cm} \quad=227 \mathrm{~mm} \\
\Phi \mathrm{di} & =206,37 \mathrm{~mm}
\end{aligned}
$$

\section{G. Luas Panas Superheat}

Kalor yang diterima oleh uap superheat adalah:

$$
\begin{aligned}
\mathrm{q}_{\mathrm{eko}} & =\mathrm{m}_{\text {uap }} \cdot \text { Cps. }\left(\mathrm{ts}_{2}-\mathrm{ts}_{1}\right) \\
& =10.000,00 \times 0,445(400
\end{aligned}
$$

$$
=769.850,00 \mathrm{kcal} / \mathrm{kg}
$$

$$
\Delta \mathrm{t}_{1}=\left(\operatorname{tg}_{\text {in }}-\mathrm{ta}_{\mathrm{ou}}\right)=(950,00 \quad-
$$$$
\text { 400,00) }=550,00{ }^{\circ} \mathrm{C}
$$$$
\Delta \mathrm{t}_{1}=\left(\mathrm{ta}_{\text {ou }}-\operatorname{tg}_{\text {in }}\right)=(620,00 \quad-
$$$$
\text { 227,00) }=393,00{ }^{\circ} \mathrm{C}
$$$$
\Delta \mathrm{t}_{\mathrm{sh}}=\frac{\Delta t 1-\Delta t 2}{\log e\left(\frac{\Delta t 1}{\Delta t 2}\right)}
$$

$$
\begin{aligned}
& =\frac{550-393}{\log e \times 2,731} \\
& =547^{0} \mathrm{C}
\end{aligned}
$$

Maka:

$$
\mathrm{A}_{\mathrm{sh}} \quad=\frac{q_{s h}}{k \Delta t_{s h}}
$$

Dimana $k$ untuk gas $\mathrm{ke}$ gas $=25,00$ $\mathrm{kcal} / \mathrm{m}^{2} \mathrm{~h}{ }^{0} \mathrm{C}$

Sehingga:

$$
\begin{aligned}
\mathrm{A}_{\mathrm{sh}} & =\frac{769.850}{25.547} \\
& =\frac{769.850}{9140} \\
& =84,20 \mathrm{~m}^{2}
\end{aligned}
$$

Jadi luas panas superheater $=84,20 \mathrm{~m}^{2}$

\section{H. Jumlah Pipa Super Heater}

$$
\begin{aligned}
\mathrm{n} & =\frac{84,2}{3,14 \times 0,038 \times 8,7} \\
& =68,50 \mathrm{bh}
\end{aligned}
$$

Jadi banyak pipa superheater $=68$ buah pipa

\subsection{Temperatur Ruang Pembakaran}

Suhu udara masuk ruang pembakaran $=$ $30,00{ }^{0} \mathrm{C}$

Panas jenis udara $=0,24$

\subsubsection{Jumlah Kebutuhan Udara} Teoritis

Kebutuhan oksigen tiap $\mathrm{t} k \mathrm{~kg}$ batubara

$$
\mathrm{C}=0,5131=0,5131 \mathrm{x}
$$

$$
\begin{array}{ll}
\frac{32}{12} & =1,368 \mathrm{kgO}_{2} \\
& \mathrm{H} \quad=0,0454 \quad=0,0454 \mathrm{x} \\
8 & =0,3632 \mathrm{kgO}_{2} \\
& \mathrm{O} \quad=0,1231 \\
& =0,1231 \mathrm{kgO}_{2} \\
\mathrm{~S} \quad=0,0 & 0,01 \\
& =\frac{0}{1,8643} \mathrm{kgO}_{2}
\end{array}
$$


Udara yang dibutuhkan:

Karena $1 \mathrm{~kg}$ udara mengandung 0,233 $\mathrm{kgO}_{2}$, sehingga udara teoritis yang dibutuhkan:

$$
\mathrm{U} \text { og }=\frac{1,8643}{0,233} \quad=8,001 \mathrm{~kg}
$$

udara

Rasio $20 \%$ Kelebihan Udara:

$$
\begin{aligned}
& =8,00+\left(\frac{20}{100} \times 0,001\right) \\
& =9,60 \mathrm{~kg} \text { udara } / \mathrm{kg} \text { bahan bakar }
\end{aligned}
$$

\subsubsection{Jumlah Gas Asap (Flue Gas)}

$\mathrm{G}_{\text {teo }}=12,435 \mathrm{C}+35,483\left(H-\frac{o}{8}\right)+$

$$
1,125 . \mathrm{O}+5,31 . \mathrm{S}+\mathrm{W}+\mathrm{N}
$$$$
=12,435(0,5131)+35,483
$$

$\left(0,0454-\frac{-0,1231}{8}\right)+1,125(0,1231)+$

8,531

$$
\begin{aligned}
& +0,14+0,0093 \\
= & 6,38+1,065+0,1384+0,5131+ \\
0,14+ & 0,0093 \\
= & 7,7858 \mathrm{~kg} \text { gas asap / } \mathrm{kg} \text { bahan }
\end{aligned}
$$

bakar

$\mathrm{G}_{\mathrm{gas}}=\mathrm{G}_{\mathrm{teo}}+\eta\left({ }^{\mathrm{A} / \mathrm{F}}\right.$ teo $)$

$\mathrm{A} / \mathrm{F}$ teo $=11,467 \mathrm{C}+34,48\left(H-\frac{o}{8}\right)+$

4.31. S

$$
\begin{aligned}
& =11,467 \quad .0,5131+34,48 \\
(0,0454 & \left.-\frac{-0,1231}{8}\right)+4.31 \cdot 0,01 \\
& =5,8837+1,0348+0,0431 \\
& =6,9616
\end{aligned}
$$

Jika, $\lambda=1,2<\left({ }^{A} / \mathrm{F}\right.$ teo $)$
$=7,7858+1,2(6,9616)$

$=7,7858+8,354$

$=16,139 \mathrm{~kg}$ gas asap $/ \mathrm{kg}$ bahan

bakar

Kalor yang dihasilkan dalam pembakaran $1 \mathrm{~kg}$ bahan bakar = kalor gas asap $1 \mathrm{~kg}$ bahan bakar.

$\mathrm{q}$ pembakaran $=\mathrm{q}$ gas asap

Dimana:

Eff ketel $(\eta)$

$=90,00 \%$

Penyinaran pada dinding ketel $=30,00 \%$

Cp gas asap $=0,265 \mathrm{kcal} / \mathrm{kg}^{0} \mathrm{C}$

Maka:

$\mathrm{q}$ pembakaran $=\mathrm{q}$ gas asap

Sehingga:

$\mathrm{q}$ pembakaran $=\mathrm{q}$ gas asap

$0,7 \times 0,90 \times 10.166,74=16,139 \times 0,265$ $\left(\mathrm{t}_{\text {api }}-30\right)$

$\begin{array}{ll}6625,54 & =3,947\left(\mathrm{t}_{\text {api }}-30\right) \\ \mathrm{t}_{\mathrm{api}} & =(6625,54 \mathrm{x}\end{array}$

$73,947)+30$

$\mathrm{t}_{\text {api }} \quad=1.420,00{ }^{\circ} \mathrm{C}$

Temperatur ruang bakar $\quad=1.420,00$ ${ }^{0} \mathrm{C} 3$

\subsubsection{Pemakaian Bahan Bakar}

Pemakaian bahan bakar tiap jam:

$$
\text { B }=\frac{G\left(h_{a}-h_{s}\right)}{\eta_{\text {boiler }} x q}
$$

(Jackson, James, J., 2012) 
Dimana:

$$
\begin{aligned}
\mathrm{G} & =\text { Kapasitas uap yang } \\
\text { dihasilkan } & =10.000,00 \mathrm{~kg} / \mathrm{jam} \\
\mathrm{h}_{\mathrm{a}} & =\text { Entalphi air masuk } \\
& =80,00 \mathrm{kcal} / \mathrm{kg} \\
\mathrm{h}_{\mathrm{a}} & =\text { Entalphi steam keluar } \\
& =773,83 \mathrm{kcal} / \mathrm{kg} \\
\eta & =\text { Efisiensi boiler } \\
& =90 \% \\
\mathrm{q} & =\text { Nilai pembakaran } \\
& =5.300,00 \mathrm{kcal} / \mathrm{jam}
\end{aligned}
$$

Maka:

$$
\begin{aligned}
\mathrm{B} & =\frac{10.000(773,83-80)}{90 \% \times 5.300} \\
& =\frac{6.938 .300}{80 \% \times 5.300} \\
& =1.617,00 \mathrm{~kg} / \mathrm{jam}
\end{aligned}
$$

\section{Kesimpulan Dan Saran}

\subsection{Kesimpulan}

Ketel uap kapasitas 10 ton/jam, dengan data-data sebagai berikut:

Kapasitas $=10,00$ ton uap/jam

Tekanan $=25,00 \mathrm{~kg} / \mathrm{cm}^{2}$

Temperatur uap keluar superheat = $400,00^{\circ} \mathrm{C}$

Bahan bakar $=$ Batubara

Nilai pembakaran $=5.300,00 \mathrm{kcal} / \mathrm{kg}$

\section{Hasil Penelitian:}

- Temperature air pengisi masuk ekonomiser $=80,00{ }^{0} \mathrm{C}$

- $\quad$ Temperature ruang bakar $=1.420,00$ ${ }^{0} \mathrm{C}$
- Pemakaian bahan bakar tiap jam = $1.617,00 \mathrm{~kg} / \mathrm{jam}$

- $\quad$ Kalor yang diterima $=6.938 .300,00$ $\mathrm{kcal} / \mathrm{k}$

- $\quad$ Temperature air keluar ekonomiser $=$ $170,00{ }^{0} \mathrm{C}$

- $\quad$ Luas panas ekonomiser $=157,90 \mathrm{~m}^{2}$

- $\quad$ Tebal pipa ekonomiser $=2,41 \mathrm{~mm}$

- Jumlah pipa ekonomiser $=84,00 \mathrm{bh}$

- Tebal pipa-pipa air $=2,75 \mathrm{~mm}$

- $\quad$ Tebal pipa air pengumpul = 5,88 $\mathrm{mm}$

- $\quad$ Luas panas pipa air $=94,60 \mathrm{~m}^{2}$

- $\quad$ Jumlah pipa air $=182,00 \mathrm{bh}$

- Tebal plat boiler drum $=22,40 \mathrm{~mm}$

- $\quad$ Tebal tutup boiler drum $=26,50 \mathrm{~mm}$

- $\quad$ Tebal pipa superheat $=2,260 \mathrm{~mm}$

- Jumlah pipa superheat $=68,00 \mathrm{bh}$

- $\quad$ Luas panas superheat $=84,20 \mathrm{~m}^{2}$

- $\quad$ Total luas panas boiler $=336,70 \mathrm{~m}^{2}$

- Kebutuhan udara pembakaran setiap jam $=9,6012 \mathrm{~kg} / \mathrm{bhn}$ bkr

- Panas yang diserap oleh boiler = $8.672 .875 \mathrm{kcal} / \mathrm{jam}$

\subsection{Saran}

Suatu ketel uap ditentukan dari pemeliharaan secara rutin/berkala sesuai dengan jadwal yang telah ditentukan dari masing-masing jenis ketel uap sesuai dengan rekomendasi pabrik pembuatnya seperti bahan material, peralatan bantu, sensor penggeraknya, dan aksesoris lainnya agar dapat bekerja sesuai dengan 
standar yang telah ditentukan, misalnya: tekanan uap, ketinggian air dalam drum, temperatur uap yang dihasilkan yaitu uap superheat, tekanan udara masuk dapur (pada blower hisap dan blower udara tekan) dan sebagainya.

\section{DAFTAR PUSTAKA}

Brown AT \& Marco SM, 2012. Introduction Heat Transfer, Hill Book Company, New York.

Direktorat Jendral Listrik dan Energi Baru Departement Pertambangan dan Energi, Audit Energi Sektor Industri, 2014, Buku I, Jakarta.
Djoko Setyardjo MJ., 2014. Pembahasan Lebih Lanjut Tentang Ketel Uap, Pradya Paramita, Jakarta.

Djoko Setyardjo MJ., 2013. Ketel Uap, Pradya Paramita, Jakarta.

National Energy Conservation Center.COGENERATION, Islamabad, Pakistan Jackson, James, J., 2012, Steam Boiler Operation, McGraw-Hill Book Company, New York.

Introduction to Heat Transfer, 2012. A.T. Brown \& S.M. Marco Mc GrawHill Book Company, New York.

Wakil M.M.EL, 2012. Intalasi Pembangkit Daya I, Penerbit Pradya Paramita, Jakarta. 